\title{
Avaliação da influência do óleo essencial de laranja em filmes de PHB/PEG
}

\author{
Evaluation of the influence of orange essential oil on PHB/PEG fillms
}

Evaluación de la influencia del aceite esencial de naranja en películas de PHB/PEG

José Carlos de Andrade Alves

ORCID: https://orcid.org/0000-0002-5904-728X Universidade Federal Rural de Pernambuco, Brasil E-mail: jcarlos17071995@gmail.com

Girlaine Santos da Silva

ORCID: https://orcid.org/0000-0002-1379-0297

Universidade Federal de Pernambuco, Brasil E-mail: lane_santos13@hotmail.com

Karina Carvalho de Souza

ORCID: https://orcid.org/0000-0002-9902-7566 Universidade Federal de Pernambuco, Brasil E-mail: karinacar_souza@hotmail.com

Ivo Diego de Lima Silva

ORCID: https://orcid.org/0000-0001-7441-2305 Universidade Federal de Pernambuco, Brasil E-mail: ivo.diego91@gmail.com

Carla Fabiana da Silva

ORCID: https://orcid.org/0000-0002-9921-5508 Universidade Federal de Pernambuco, Brasil E-mail: carlinha.flordelis@gmail.com

Viviane Fonseca Caetano

ORCID: https://orcid.org/0000-0002-8517-8312 Universidade Federal de Pernambuco, Brasil E-mail: viviane fc@yahoo.com.br

Glória Maria Vinhas

ORCID: https://orcid.org/0000-0001-5073-609X

Universidade Federal de Pernambuco, Brasil E-mail: viviane_fc@yahoo.com.br

\begin{abstract}
Resumo
Uma alternativa para reduzir o uso de polímeros degradáveis são os biopolímeros. Dentre eles, destaca-se o poli(3hidroxibutirato) - PHB que é um termoplástico semicristalino biodegradável obtido a partir de fontes naturais renováveis. Nesse contexto, foram desenvolvidas blendas de PHB/PEG aditivadas com 0, 5, 10 e $15 \% \mathrm{~m} / \mathrm{m}$ de óleo essencial de laranja através da técnica solution casting. Os filmes foram caracterizados por infravermelho médio, Análise por Componentes Principais e propriedades mecânicas. Os componentes presentes no óleo essencial de laranja foram identificados através de espectrometria de massa por cromatografia gasosa e foi realizado o método de difusão de disco para avaliar a atividade antimicrobiana. Os resultados mostraram que o componente majoritário no óleo essencial de laranja é o d-limoneno e que possui atividade antimicrobiana perante as bactérias $S$. aureus e E. coli. Também foi confirmada a presença do componente majoritário na blenda PHB/PEG por FTIR/PCA. Os resultados mecânicos mostraram que a aditivação de $10 \%$ e $15 \% \mathrm{~m} / \mathrm{m}$ tornou os filmes mais resistentes mecanicamente e com maior rigidez. Os filmes de PHB/PEG/OEL mostraram ter potencial para serem aplicados como embalagens alimentícias antimicrobianas.
\end{abstract}

Palavras-chave: PHB; PEG; Óleo essencial de laranja.

\begin{abstract}
An alternative to reduce the use of degradable polymers is biopolymers. Among them, poly (3-hydroxybutyrate) - PHB stands out, which is a biodegradable semicrystalline thermoplastic obtained from natural renewable sources. In this context, PHB / PEG blends with 0, 5, 10 and $15 \% \mathrm{w} / \mathrm{w}$ of orange essential oil were developed using the solution casting technique. The films were characterized by medium infrared, Principal Component Analysis and mechanical properties. The components present in the orange essential oil were identified by mass spectrometry by gas chromatography and the disk diffusion method was used to evaluate the antimicrobial activity. The results showed that the major component in orange essential oil is d-limonene and that it has antimicrobial activity against the bacteria S. aureus and E. coli. The presence of the major component in the PHB / PEG blend was also confirmed by FTIR / PCA. The mechanical results
\end{abstract}


showed that the additives of $10 \%$ and $15 \% \mathrm{w} / \mathrm{w}$ made the films more mechanically resistant and with greater rigidity. PHB/PEG/OEL films have shown the potential to be applied as antimicrobial food packaging.

Keywords: PHB; PEG; Orange essential oil.

\begin{abstract}
Resumen
Una alternativa para reducir el uso de polímeros degradables son los biopolímeros. Entre ellos destaca el poli (3hidroxibutirato) - PHB, que es un termoplástico semicristalino biodegradable obtenido de fuentes naturales renovables. En este contexto, se desarrollaron mezclas de PHB/PEG con 0, 5, 10 y $15 \% \mathrm{~m} / \mathrm{m}$ de aceite esencial de naranja utilizando la técnica de fundición en solución. Las películas se caracterizaron por infrarrojo medio, análisis de componentes principales y propiedades mecánicas. Los componentes presentes en el aceite esencial de naranja se identificaron mediante espectrometría de masas mediante cromatografía de gases y se utilizó el método de difusión en disco para evaluar la actividad antimicrobiana. Los resultados mostraron que el componente principal del aceite esencial de naranja es el d-limoneno y que tiene actividad antimicrobiana contra las bacterias $S$. aureus y E. coli. La presencia del componente principal en la mezcla PHB / PEG también fue confirmada por FTIR/ PCA. Los resultados mecánicos mostraron que los aditivos de $10 \%$ y $15 \% \mathrm{~m} / \mathrm{m}$ hicieron que las películas fueran más resistentes mecánicamente y con mayor rigidez. Las películas PHB/PEG/OEL han demostrado el potencial de ser aplicadas como empaques de alimentos antimicrobianos.
\end{abstract}

Palabras clave: PHB; PEG; Aceite esencial de naranja.

\title{
1. Introdução
}

Os plásticos sintéticos e derivados do petróleo são vistos como contaminantes ecológicos graves, pois levam décadas para se decompor e ainda produzem toxinas durante o seu processo de degradação (Sirohi, et al., 2020). Nesse contexto, tem-se as embalagens plásticas de alimentos que contribuem de forma relevante para a poluição mundial (Manikandan, et al., 2020). Uma alternativa ecologicamente correta para a substituição desses materiais são os biopolímeros, que podem ser usados para permutar os plásticos não biodegradáveis, reduzindo o impacto ambiental e a petro-dependência (Zhong, et al., 2020). Dentre os biopolímeros ressaltam-se os poli-hidroxialcanoatos (PHAs), que são biodegradáveis, termoestáveis, resistentes a UV, insolúveis em água, biocompatíveis e renováveis (Deshmukh, et al., 2020).

Um tipo de PHAs com grande potencialidade para o setor de embalagens é o poli(3-hidroxibutirato) - PHB, que é um biopolímero termoplástico semicristalino biodegradável obtido a partir de fontes naturais renováveis (Hoffmann, et al., 2019; Costa, et al., 2019). O PHB é adequado para aplicações em embalagens alimentícias devido as suas excelentes propriedades de barreira de aroma, além da permeabilidade ao vapor de água (Zhong, et al., 2020). No entanto, o PHB tem desvantagem em relação a sua estreita janela de processamento e a sua fragilização ao longo do tempo devido à cristalização secundária (Plavec, et al., 2020; Kelly, et al., 2018). Para compensar essa desvantagem pode-se adicionar a esse polímero agentes plastificantes, como por exemplo o polietilenoglicol (PEG), polímero atóxico e biodegradável que quando misturado a outros polímeros pode proporcionar efeito plastificante (Fiori, et al., 2019).

As blendas PHB/PEG podem ser aditivadas com outras substâncias que proporcionem propriedades diferenciadas, como antimicrobiana, por exemplo. Os óleos essenciais são misturas complexas de metabólitos secundários isolados de várias plantas que podem apresentar propriedades bactericidas, virucidas e/ou fungicidas, além de melhorar as propriedades funcionais e mecânicas dos filmes (Do Evangelho, et al., 2019; Azeredo \& Soares, 2013). Dentre os óleos essenciais tem-se o óleo essencial de laranja que é um subproduto obtido a partir dos resíduos gerados no processamento dessa fruta para a produção de sucos (Bizzo, et al., 2009). Segundo Santos, et al. 2020, o Brasil é o maior produtor de laranja do mundo e gera em média 40 a $50 \%$ de resíduos dessa fruta. A ação antimicrobiana do óleo essencial de laranja deve-se ao d-limoneno, componente majoritário presente nesse óleo.

$\mathrm{Na}$ literatura existem trabalhos que avaliaram a incorporação do óleo essencial de laranja em matrizes poliméricas, como amido de milho (Do Evangelho et al., 2019), nanoemulsões de quitosana (Bento, et al., 2020), poli(butileno adipato cotereftalato) (De Andrade, et al., 2020) e poli(cloreto de vinila) (Da Silva, et al., 2018).

Neste trabalho, foi avaliado a incorporação do óleo essencial de laranja em filmes de blendas poliméricas de PHB/PEG 
através de suas propriedades mecânicas e a atividade antimicrobiana do óleo testado visando sua utilização futura em embalagens alimentícias.

\section{Metodologia}

\subsection{Materiais}

O poli(3-hidroxibutirato) - PHB em pó foi doado pela PHB Industrial. O óleo essencial de laranja (densidade = 0,82 $\mathrm{g} / \mathrm{mL}$ ) foi doado pela Agroterenas. O solvente clorofórmio e o plastificante polietilenoglicol utilizados são das marcas Quimex e Vetec respectivamente. O PEG utilizado possui massa molar média de $6000 \mathrm{~g} / \mathrm{mol}$.

\subsection{GC-MS do óleo essencial de laranja}

Os componentes presentes no óleo essencial de laranja foram identificados através de espectrometria de massa por cromatografia gasosa (Gas chromatography mass spectrometry - GC-MS) utilizando um cromatógrafo da marca Thermo Scientific, modelo 1300 e espectrômetro de massa ISQ Single sistema quadrupolo. Os parâmetros de análise foram: temperatura de rampa de forno do $\mathrm{GC}=60^{\circ} \mathrm{C}$ por $3 \mathrm{~min}$; taxa de aquecimento de $10^{\circ} \mathrm{C} / \mathrm{min}$ até atingir a temperatura de $300^{\circ} \mathrm{C}$; após atingir essa temperatura, essa é mantida por $15 \mathrm{~min}$; temperatura do injetor $270^{\circ} \mathrm{C}$; temperatura da linha de transferência para o MS de $280^{\circ} \mathrm{C}$; e temperatura da fonte de íons do MS de $250^{\circ} \mathrm{C}$.

\subsection{Atividade antimicrobiana do óleo essencial de laranja}

A atividade do óleo essencial de laranja foi avaliada através do método de difusão de disco (Nagy, et al., 2015) utilizando o meio Ágar padrão para contagem bacteriana (Plate Count Agar - PCA). Para a realização desse método, foram utilizados discos de papel de filtro de diâmetro $2 \mathrm{~cm}$ que foram esterilizados por radiação UV por $5 \mathrm{~min}$ em ambos os lados. Foram utilizadas alíquotas de 0,5 mL de S. aureus (ATCC 6538) e E. coli (ATCC 8739) na ordem de 107 UFC/mL, obtidas pela comparação de turvação na escala de Mcfarland. Essas bactérias foram inoculadas no meio de cultura PCA pelo método de inoculação em profundidade (pour plate). Após a solidificação do meio, foram dispostos os discos imersos no óleo essencial de laranja, no centro da placa de Petri. As placas foram incubadas em estufa a $35^{\circ} \mathrm{C}$ durante $48 \mathrm{~h}$. Após esse período a atividade antimicrobiana foi avaliada.

\subsection{Preparação dos filmes}

Os filmes foram produzidos através da técnica de solution casting (Martelli, et al., 2012). Para isso, foi utilizado uma massa total de 1,4 g para cada filme, com composição de $90 \% \mathrm{~m} / \mathrm{m}$ de PHB e $10 \% \mathrm{~m} / \mathrm{m}$ de PEG $6000 \mathrm{~g} / \mathrm{mol}$. Para a preparação de cada filme de PHB/PEG foi dissolvido $1,26 \mathrm{~g}$ de PHB em $50 \mathrm{ml}$ de clorofórmio e colocado sob agitação por 5 horas a $60^{\circ} \mathrm{C}$. Terminado esse tempo, a solução foi deixada sob repouso por 12 horas. Posteriormente, a solução foi colocada novamente por agitação por 4 horas à temperatura ambiente, para que ocorresse a dissolução das partículas que não foram dissolvidas durante a primeira agitação sob aquecimento. Com o término do período, a solução é filtrada, adiciona-se $0,14 \mathrm{~g}$ de PEG e coloca-se esse sistema sob agitação à temperatura ambiente por $1 \mathrm{~h}$. Finalizado esse tempo, essa solução foi vertida na placa de Petri sob repouso à temperatura ambiente até que se tenha a evaporação total do solvente.

Para a preparação dos filmes PHB/PEG/OEL, repete-se o procedimento anterior com a adição do OEL após o período de homogeneização do PEG. O OEL foi adicionado nas quantidades de 5, 10 e $15 \% \mathrm{~m} / \mathrm{m}$ em relação a massa de $90 \% \mathrm{~m} / \mathrm{m}$ de PHB. A massa de PEG é constante na formulação de todos os filmes. 


\subsection{Aquisição de espectros de infravermelho médio}

Os espectros de infravermelho médio dos filmes foram registrados utilizando um espectrômetro Spectrum 400 FTIT/FT-NIR da marca Perkin Elmer, com acessório de reflexão atenuada total horizontal (Horizontal Attenuated Total Reflectance-HATR), nas seguintes condições: região espectral de 4000 a $650 \mathrm{~cm}^{-1}$, com resolução de $4 \mathrm{~cm}^{-1}$ e 16 varreduras. Para a realização da Análise por Componentes Principais foi utilizado o software The Unscrambler.

\subsection{Ensaios mecânicos dos filmes}

Os ensaios mecânicos dos filmes foram realizados na máquina universal de ensaio de tração modelo DL-500MF da marca EMIC seguindo a norma ASTM D882-12. Os ensaios ocorreram à temperatura ambiente e sem controle de umidade. Os ensaios foram realizados nas seguintes condições: célula de carga de $500 \mathrm{~N}$; velocidade da garra de $5 \mathrm{~mm} / \mathrm{min}$; distância inicial entre as garras de $40 \mathrm{~mm}$; e dimensão do corpo de prova de $2.5 \times 7.5 \mathrm{~cm}$.

\section{Resultados e Discussão}

\subsection{Caracterização do óleo por GC-MS}

A Figura 1 ilustra o cromatograma obtido através do GC-MS para o óleo essencial de laranja. Foram detectados 150 componentes nesse óleo. Verificou-se que os componentes p-Mentha-1(7).3-dieno, d-limoneno e ácido cis-13-octadecenóico apresentaram os maiores picos de intensidade no cromatograma.

Figura 1. Cromatograma obtido por GC-MS do óleo essencial de laranja.

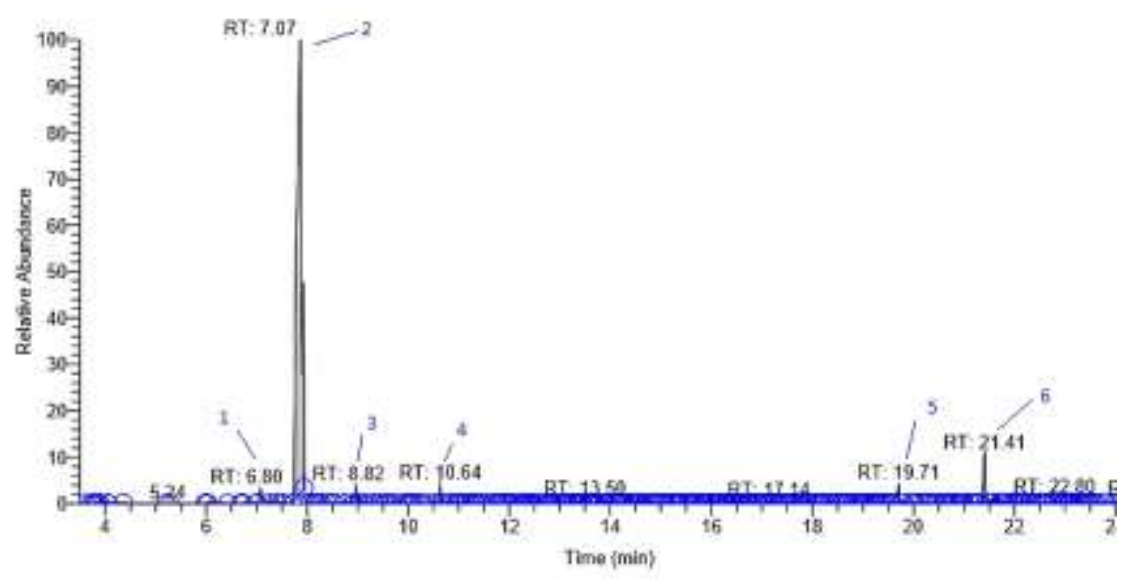

Fonte: Autores.

O d-limoneno apresentou-se de forma majoritária e de forma mais significativa (79.97\%) no óleo essencial de laranja. Os valores referentes aos seus tempos de retenção (RT) e percentuais dos picos áreas para esses componentes encontram-se na Tabela 1. 
Tabela 1. Principais componentes do óleo essencial de laranja obtidos pelo GC-MS.

\begin{tabular}{cccc}
\hline $\begin{array}{c}\text { Número no } \\
\text { cromatograma }\end{array}$ & Componente & $\begin{array}{c}\text { Tempo de } \\
\text { retenção }(\mathbf{R T}) \\
(\mathbf{m i n})\end{array}$ & Pico área (\%) \\
\hline 1 & p-Mentha-1(7).3-dieno & 6,80 & 1,98 \\
2 & d-limoneno & 7,07 & 79,97 \\
6 & ácido cis-13-octadecenóico & 21,41 & 3,95 \\
\hline
\end{tabular}

Fonte: Autores.

$\mathrm{Na}$ literatura são encontrados outros autores que também encontraram o d-limoneno como componente principal do óleo essencial de laranja, dentre eles tem-se De Andrade, et al., (2020) e Da Silva, et al., 2018.

\subsection{Análise de atividade antimicrobiana do óleo essencial de laranja}

Conforme pode ser visualizado na Figura $2 \mathrm{a}$ e $2 \mathrm{~b}$, através da formação dos halos de inibição (destacados de linha pontilhada branca), o óleo essencial de laranja apresentou atividade antimicrobiana quando exposto as bactérias Staphylococcus aureus e Escherichia coli.

Figura 2. Método de difusão de disco para o óleo essencial de laranja exposto aos microrganismos (a) S.aureus (b) E.coli.

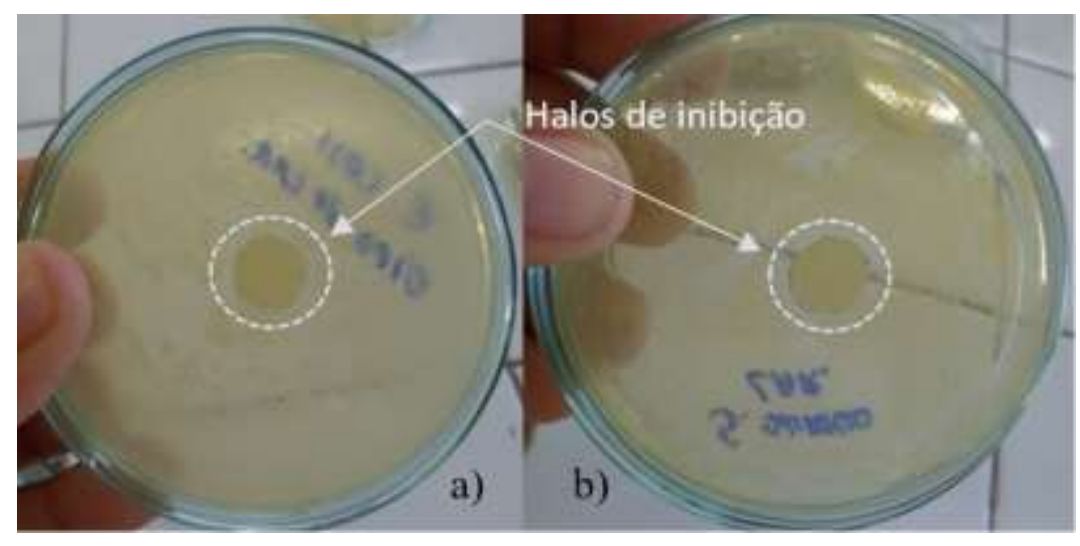

Fonte: Autores.

Os halos de inibição apresentaram os seguintes diâmetros $21 \mathrm{~mm}$ e $38 \mathrm{~mm}$ nos testes contra as bactérias $S$. aureus e $E$. Coli, respectivamente. Esses resultados corrolaboram com os encontrados por Silva, et al., 2018 e Edogbanya, et al., 2019.

\subsection{Espectros de infravermelho médio}

A Figura 3 ilustra os espectros representativos obtidos a partir das análises de infravermelho médio do óleo essencial de laranja (OEL), filmes de PHB/PEG aditivados com óleo essencial de laranja nas composições de $0 \% \mathrm{~m} / \mathrm{m}$ (PHB/PEG), $5 \%$ $\mathrm{m} / \mathrm{m}$ (PHB/PEG5\% OEL), $10 \%$ m/m (PHB/10\% OEL) e 15\% m/m (PHB/15\% OEL). 
Figura 3. Espectros representativos do óleo essencial de laranja (OEL) e dos filmes de PHB/PEG/OEL nas composições de 0 a $15 \%$ de óleo essencial de laranja.

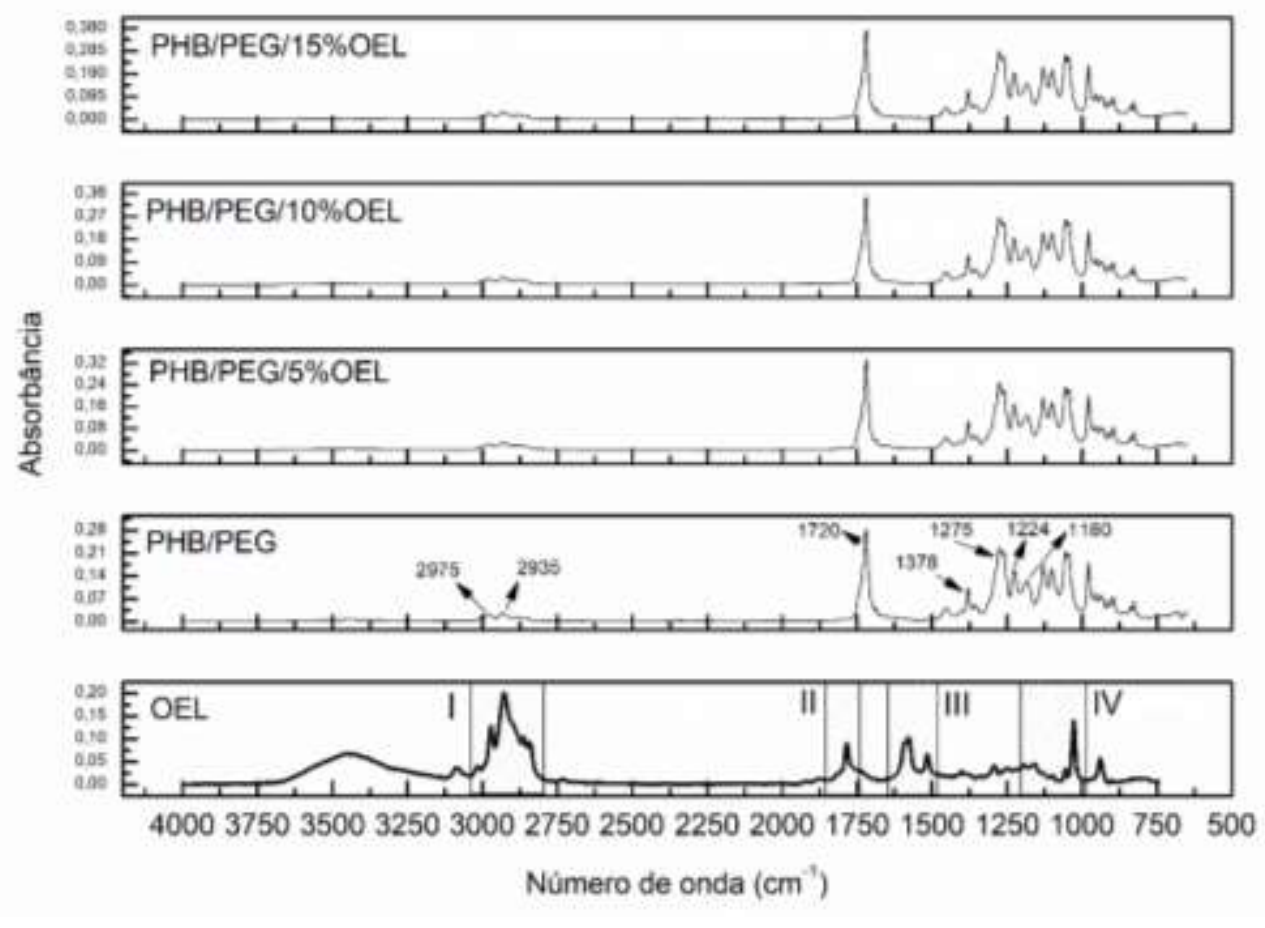

Fonte: Autores.

No espectro do OEL, como foi constatado também no cromatograma do GC-MS, o d-limoneno é o componente em maior quantidade. Os picos máximos referentes as suas bandas características podem ser visualizadas nas regiões I, II, III e IV que correspondem a deformação axial dos grupos $\mathrm{CH}_{3}, \mathrm{CH}_{2}$ e $\mathrm{CH}$; deformação axial do grupo $\mathrm{C}=\mathrm{C}$; modo de deformação do $\mathrm{CH}_{2}$ e $\mathrm{CH}_{3}$; e deformação angular do C-H (Zapata, et al., 2009). Nos espectros do PHB/PEG/OEL de 0 a $15 \% \mathrm{~m} / \mathrm{m}$, podem ser visualizados os picos máximos referentes as bandas características do PHB em 2975, 2935, 1720, 1378, 1275, 1224 e $1180 \mathrm{~cm}$ ${ }_{1}^{1}$ que correspondem ao estiramento $\mathrm{CH}_{3}$, estiramento $\mathrm{CH}_{2}$, estiramento $\mathrm{C}=\mathrm{O}$, deformação angular $\mathrm{CH}_{3}$, estiramento $\mathrm{C}-\mathrm{O}$, deformação angular $\mathrm{CH}_{2}$ e estiramento $\mathrm{C}-\mathrm{O}$, respectivamente (Perveen et al., 2020). Nos espectros do PHB/PEG/OEL não é possível visualizar as bandas características do PEG e nem do OEL, provavelmente devido a sobreposição de bandas ou a baixa concentração de óleo em relação a matriz polimérica. Para confirmar a incorporação do OEL na matriz polimérica do PHB/PEG foi realizada a Análise por Componentes Principais. Essa técnica quimiométrica tem como um dos seus objetivos encontrar similaridades entre as amostras avaliadas (De Souza \& Poppi, 2012), no caso os dados espectrais obtidos por infravermelho médio. Na Figura 4 é ilustrado o gráfico dos escores. Esse gráfico representa as coordenadas das amostras no espaço das componentes principais (PC's). 
Figura 4. Gráfico dos escores da PC1xPC2 dos filmes de PHB/PEG/OEL.

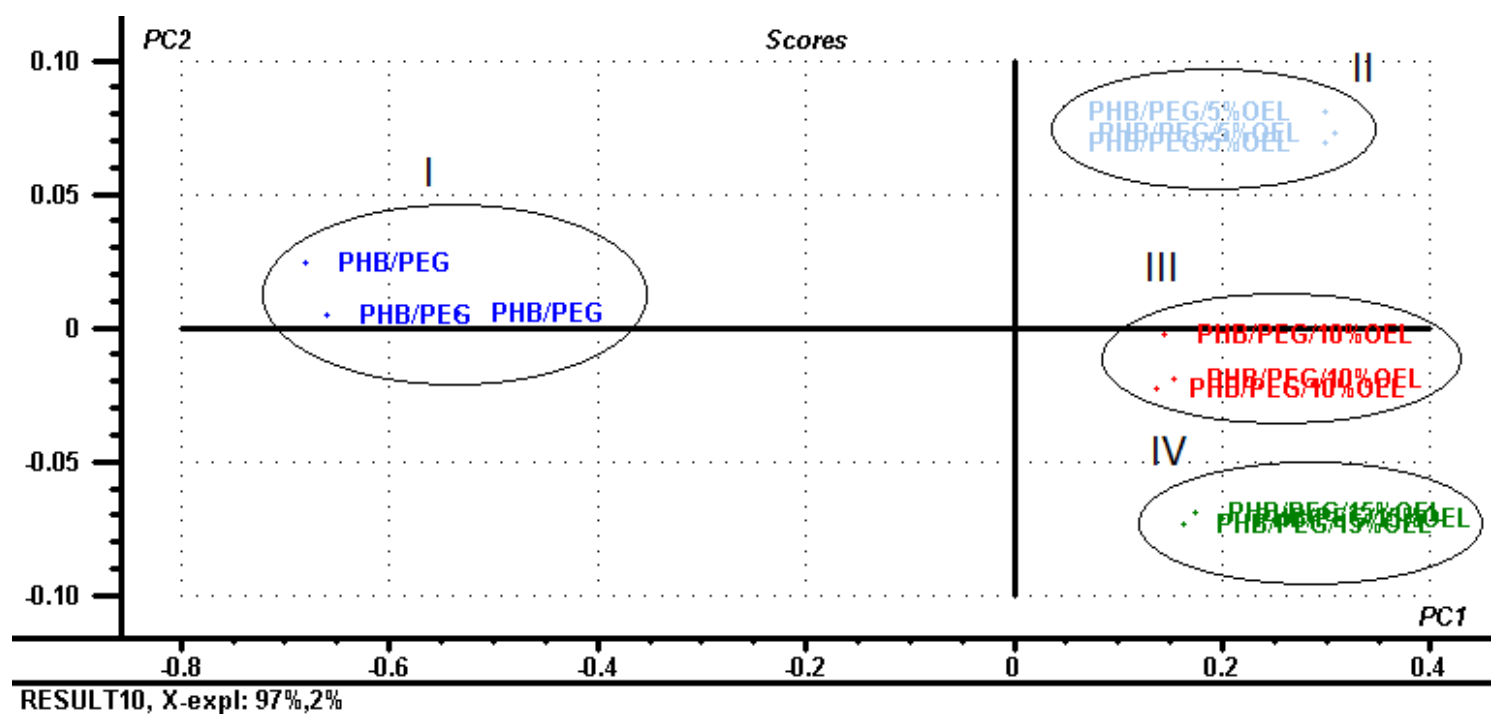

Fonte: Autores.

Observa-se, na Figura 4, que a PCA separou as amostras em grupos distintos (I, II, III e IV) evidenciando que houve a incorporação de óleo essencial de laranja na matriz polimérica. Os grupos I, II, III e IV são referentes aos filmes de PHB/PEG (PHB/PEG), PHB/PEG aditivado com 5\% de óleo essencial de laranja (PHB/PEG/5\%OEL), PHB/PEG aditivado com 10\% de óleo essencial de laranja (PHB/PEG/10\%OEL) e PHB/PEG aditivado com 15\% de óleo essencial de laranja (PHB/PEG/15\%OEL), respectivamente. A porcentagem de variância explicada pela PC1 e PC2 foi 97\% e 2\%, respectivamente.

\subsection{Ensaios mecânicos}

Na Tabela 2 são mostrados os valores obtidos através dos ensaios mecânicos para as propriedades mecânicas (Mano, 2019) resistência à tração na ruptura, percentual de alongamento na ruptura e módulo de elasticidade, respectivamente, para PHB/PEG, PHB/PEG/5\%OEL, PHB/PEG/10\%OEL e PHB/PEG/15\%OEL. Os valores médios das propriedades mecânicas obtidas através das propriedades mecânicas foram comparados estatisticamente pelo teste de Duncan com nível de significância de $5 \%(\mathrm{p}<0,05)$.

Tabela 2. Valores médios obtidos para as propriedades mecânicas.

\begin{tabular}{cccc}
\hline Amostra & $\begin{array}{c}\text { Tensão na ruptura } \\
(\mathbf{M P a})^{*}\end{array}$ & $\begin{array}{c}\text { Percentual de } \\
\text { alongamento na } \\
\text { ruptura }(\%)^{*}\end{array}$ & $\begin{array}{c}\text { Módulo de } \\
\text { elasticidade (MPa)* }\end{array}$ \\
\hline PHB/PEG & $11,894^{\mathbf{a}} \pm 1,619$ & $3,492^{\mathbf{a}} \pm 1,144$ & $415,23^{\mathrm{a}, \mathrm{b}} \pm 40,44$ \\
$\mathrm{PHB} / \mathrm{PEG} / 5 \% \mathrm{OEL}$ & $12,020^{\mathbf{a}} \pm 1,334$ & $2,396^{\mathbf{b}} \pm 0,143$ & $397,25^{\mathbf{a}} \pm 48,49$ \\
$\mathrm{PHB} / \mathrm{PEG} / 10 \% \mathrm{OEL}$ & $17,185^{\mathbf{b}} \pm 0,728$ & $3,471^{\mathbf{a}} \pm 0,266$ & $465,30^{\mathbf{b}} \pm 59,14$ \\
$\mathrm{PHB} / \mathrm{PEG} / 15 \% \mathrm{OEL}$ & $16,948^{\mathbf{b}} \pm 1,623$ & $3,647^{\mathbf{a}} \pm 0,489$ & $469,62^{\mathbf{b}} \pm 31,22$ \\
\hline
\end{tabular}

*Médias com as mesmas letras na mesma coluna não diferem com p<0,05 pelo Teste de Duncan. Fonte: Autores.

Analisando-se os resultados obtidos através dos ensaios mecânicos da Tabela 2, observa-se diferenças estatísticas para um nível de confiança de 5\% para as propriedades mecânicas avaliadas com a adição do óleo essencial de laranja na matriz polimérica. Para a tensão na ruptura, foi observado um aumento no valor dessa propriedade a partir da adição de $10 \%$ de OEL, 
tornando o filme mais resistente mecanicamente. Para o percentual de alongamento não foram observadas diferenças estatísticas, exceto para a composição com a incorporação de 5\% de OEL que apresentou uma diminuição no valor dessa propriedade, o que torna o filme menos elástico. Para o módulo de elasticidade, não foi observado alterações significativas, exceto também para a formulação com a aditivação de 5\% que apresentou um valor menor para essa propriedade quando se compara com as formulações aditivadas com 10 e $15 \%$. O aumento do valor do módulo de elasticidade proporciona uma maior rigidez ao filme polimérico. Na literatura, tem-se o trabalho de Silva, et al., 2020 que incorporou óleo essencial de cravo na matriz polimérica do PHB/PEG. O óleo essencial de cravo atuou de forma contrária ao óleo essencial de laranja nessa mesma matriz polimérica, pois tornou o filme menos resistente mecanicamente e mais flexível.

\section{Conclusão}

Com base nos resultados da Análise por Componentes Principais é possível confirmar que houve a incorporação do óleo essencial de laranja na matriz polimérica do PHB/PEG em diferentes composições. Verificou-se também que a partir da incorporação de $10 \% \mathrm{~m} / \mathrm{m}$ de OEL, os filmes tornam-se mais resistentes mecanicamente e mais rígidos. O OEL testado apresentou atividade antimicrobiana perante patógenos relevantes na área de alimentos. Os filmes PHB/PEG/OEL possuem grande potencial para serem aplicados em embalagens alimentícias antimicrobianas. Como sugestão de trabalhos futuros, pode ser realizado teste de atividade antimicrobiana com os filmes de PHB/PEG/OEL.

\section{Referências}

Azeredo, C. M. O., \& Soares, M. J. (2013). Combination of the essential oil constituents citral, eugenol and thymol enhance their inhibitory effect on Crithidia fasciculata and Trypanosoma cruzi growth. Revista Brasileira de Farmacognosia, 23(5), 762-768. 10.1590/S0102-695X2013000500007

Bento, R., Pagán, E., Berdejo, D., De Carvalho, R. J., García-Embid, S., Maggi, F., De Souza, M. M., Leite, E., García-Gonzalo, D., \& Pagán, R. (2020). Chitosan nanoemulsions of cold-pressed orange essential oil to preserve fruit juices. International Journal of Food Microbiology, 331, 108786. 10.1016/j.ijfoodmicro.2020.108786

Bizzo, H. R., Hovell, A. M. C., \& Rezende, C. M. (2009). Óleos essenciais no Brasil: aspectos gerais, desenvolvimento e perspectivas. Química Nova, 32(3), 588-594. 10.1590/S0100-40422009000300005

Costa, A. R. M., Ito, E. N., Cavalho, L. H., \& Canedo, E. L. (2019). Impact of the natural filler babassu on the processing and properties of PBAT/PHB films. Composites Part A: Applied Science and Manufacturing, 124, 105472. 10.1016/j.compositesa.2019.105472

Da Silva, C. F., De Oliveira, F. S. M., Caetano, V. F., Vinhas, G. M., \& Cardoso, S. A. (2018). Orange essential oil as antimicrobial additives in poly(vinyl chloride) films. Polímeros: Ciência e Tecnologia, 28(4), 332-338. 10.1590/0104-1428.16216

De Andrade, M. F., Silva, I. D. L., Da Silva, G. A., Cavalcante, P. V. D., Da Silva, F. T., De Almeida, Y. M. B., Vinhas, G. M., \& De Carvalho, L. H. (2020). A study of poly (butylene adipate-co-terephthalate)/orange essential oil films for application in active antimicrobial packaging. LWT - Food Science and Technology, 125, 109148. 10.1016/j.lwt.2020.109148

De Souza, A. M. \& Poppi, R. J. (2012). Experimento didático de quimiometria para análise exploratória de óleos vegetais comestíveis por espectroscopia no infravermelho médio e Análise de Componentes Principais: Um tutorial, parte I. Química Nova, 35(1), 223-229. 10.1590/S0100-40422012000100039.

Deshmukh, A. D., Pawar, S. V., \& Rathod, V. K. (2020). Ultrasound-assisted fermentative production of Polyhydroxybutyrate (PHB) in Cupriavidus necator. Chemical Engineering and Processing - Process Intensification, 153, 107923. 10.1016/j.cep.2020.107923

Do Evangelho, J. A., Dannenberg, G. S., Biduski, B., Halal, S. L. M., Kringel, D. H., Gularte, M. A., Fiorentini, A. M., \& Zavareze, E. R. (2019). Antibacterial activity, optical, mechanical, and barrier properties of corn starch films containing orange essential oil. Carbohydrate Polymers, 222, 114981, 10.1016/j.carbpol.2019.114981

Edogbanya, P. R. O., Suleiman, M. O., Olorunmola, J. B., \& Oijagbe, I. J. (2019). Comparative study on the antimicrobial effects of essential oils from peels of three citrus fruits. MOJ Biology and Medicine, 4(2), 49-54. 10.15406/mojbm.2019.04.00113

Fiori, A. P. S. M., Camani, P. H., Dos Santos, R. D., \& Carastan, D. J. (2019). Combined effects of clay minerals and polyethylene glycol in the mechanical and water barrier properties of carboxymethylcellulose films. Industrial Crops and Products, 140, 111644. 10.1016/j.indcrop.2019.111644

Hoffmann, R., Morais, D. D. S., Braz, C. J. F., Haag, K., Wellen, R. M. R., Canedo, E. L., De Carvalho, L. H., \& Koschek, K. (2019). Impact of the natural filler babassu on the processing and properties of PBAT/PHB films. Composites Part A: Applied Science and Manufacturing, 124, 105472. 10.1016/j.compositesa.2019.105472

Kelly, C. A., Fitzgerald, A. V. L., \& Jenkins, M. J. (2018). Control of the secondary crystallisation process in poly(hydroxybutyrate-co-hydroxyvalerate) through the incorporation of poly(ethylene glycol). Polymer Degradation and Stability, 148, 67-74. 10.1016/j.polymdegradstab.2018.01.003 
Research, Society and Development, v. 10, n. 2, e30810212547, 2021

(CC BY 4.0) | ISSN 2525-3409 | DOI: http://dx.doi.org/10.33448/rsd-v10i2.12547

Manikandan, N. A., Kannan, P., \& Pugazhenthi, G. (2020). A closed-loop biorefinery approach for polyhydroxybutyrate (PHB) production using sugars from carob pods as the sole raw material and downstream processing using the co-product lignina. Bioresource Technology, $307,123247$. 10.1016/j.biortech.2020.123247.

Mano, E. B. (2019). Polímeros como materiais de engenharia. Editora Edgard Blucher Ltda.

Martelli, S. M., Sabirova, J., Fakhouri, F. M., Dyzma, A., De Meyer, B., \& Soetaert, W. (2012). Obtention and characterization of poly(3-hydroxybutyricacidco-hydroxyvaleric acid)/mcl-PHA based blends. LWT - Food Science and Technology, 47(2), 386-392. 10.1016/j.lwt.2012.01.036

Nagy, E., Justesen, U. S., Eitel, Z., \& Urbán, E. (2015). Development of EUCAST disk diffusion method for susceptibility testing of the Bacteroides fragilis group isolates. Anaerobe, 31, 65-71. 10.1016/j.anaerobe.2014.10.008.

Perveen, K., Masood, F., \& Hameed, A. (2020). Preparation, characterization and evaluation of antibacterial properties of epirubicin loaded PHB and PHBV nanoparticles. International Journal of Biological Macromolecules, 144, 259-266. 10.1016/j.ijbiomac.2019.12.049

Plavec, R., Hlaváčiková, S., Omaníková, L., Feranc, J., Vanovčanová, Z., Tomanová, K., Bočkaj, J., Kruželák, J., Medlenová, E., Gálisová, I., Danišová, L., Přikryl, R., Figalla, S., Melčová, V., \& Alexy, P. (2020). Recycling possibilities of bioplastics based on PLA/PHB blends. Polymer Testing, 92 , 106880. 10.1016/j.polymertesting.2020.106880.

Sirohi, R., Prakash, P. J., Kumar, G. V., Gnansounou, E., \& Sindhu, R. (2020). Critical overview of biomass feedstocks as sustainable substrates for the production of polyhydroxybutyrate (PHB). Bioresource Technology, 311, 123536. 10.1016/j.biortech.2020.123536.

Zapata, R. B., Villa, A. L., De Correa, C. M., \& Williams, C. T. (2009). In situ Fourier transform infrared spectroscopic studies of limonene epoxidation over PW-Amberlite. Applied Catalysis A: General, 365(1), 42-47. 10.1016/j.apcata.2009.05.047.

Zhong, Y., Godwin, P., Jin, Y., \& Xiao, H. (2020). Biodegradable polymers and green-based antimicrobial packaging materials: A mini-review. Advanced Industrial and Engineering Polymer Research, 3(1), 27-35. 10.1016/j.aiepr.2019.11.002. 